\title{
Stress-Relaxation Behavior of Inconel 718 in thermal and in-pile conditions
}

\author{
C. Getrey 1, D. Gilbon 1, T. Magnin ${ }^{2}$ and J.M. Cloué ${ }^{3}$ \\ 1 : CEA, DTA/CEREM/DTM-SRMA, C.E.N. Saclay, 91191 Gif/Yvette,FRANCE \\ 2 : Ecole des Mines de St Etienne, Département matériaux, FRANCE \\ 3 : FRAMATOME, Division Combustible, Lyon, FRANCE
}

ABSTRACT: Ni-base Superalloys are widely used in the manufacturing of spring materials which are used in the fuel rod assemblies of PWR's, because they have very high tensile strength and sufficient ductility. During their life in the reactor at a temperature of about $315^{\circ} \mathrm{C}$, the pressure exerted by these springs decreases by the effect of neutron irradiation, and might become insufficient for long term applications. The aim of this paper is to study the stress-relaxation behavior of the Inconel 718 in thermal and in-reactor conditions.

At first, we describe the experimental device allowing us to irradiate Inc 718 bending strips in Metallurgical Test Reactors (Siloé and Osiris), and to measure the stress- and strain- relaxation ratio after each irradiation period. The results of these experimental irradiations allow us to study the evolution of this ratio with irradiation time (up to 3600 hours), initial stress level (300-900 N/mm²) and metallurgical condition (Solution-Annealed and Aged or Cold-Worked and Aged). We deduce two deformation stages from calculation of plastic deformation resulting of stress-relaxation. Secondly, we use the results of out-of-pile relaxation tests to highlight the main differences induced by irradiation. Finally, we will discuss the validity of thermal relaxation models with respect to the relaxation under irradiation, and we will show the first results of examinations by transmission electron microscopy which should reveal the microstructural origin of the irradiation-induced behavior. 